\title{
CAUSES OF DELAYED HOSPITALIZATION IN PERIAMPULLARY CARCINOMA AND ITS CORRELATION WITH PERIOPERATIVE OUTCOME
}

\author{
SOBHAN AS ${ }^{1}$, KHAN AS $^{2}$, DAS BC ${ }^{3}$, CHOWDHURY MM $^{4}$, KHAN MZR $^{5}$, SHARMIN F ${ }^{6}$ \\ J Dhaka Med Coll. 2015; 24(1) : 17-23.
}

\section{Introduction}

Periampullary cancers include adenocarcinomas arising from the pancreas, ampulla of Vater, and distal common bile duct. Although the perioperative outcomes for these tumors are similar, the long-term survival has traditionally varied ${ }^{1-3}$. It is unknown why outcome varies for adenocarcinomas arising from anatomic sites in such close proximity. It is also uncertain whether this discrepancy in survival is due to different biologic behavior among tumor types or simply secondary to stage bias. Given that the majority of periampullary structures originate embryologically from the foregut, one would expect biologic behavior and pattern of cancer spread to be similar for pancreatic, ampullary, and distal bile duct cancers ${ }^{4}$. However, anatomical or embryological factors are likely to contribute little to differences in outcome ${ }^{1-4}$. Pancreatic carcinoma is an aggressive disease in comparison with other periampullary carcinoma. Majority of these patients are not operable at diagnosis due to advanced tumour stage or age, in combination with other medical disorders. Thus, attempted curative resection can only be offered to $10-20 \%$ of the patients, whereas the majority receives palliative treatment $\mathrm{t}^{3-5}$. Periampullary carcinoma though of similar embryologic origin and receiving similar surgical treatment, cancers of the ampulla of Vater are typically considered to have favorable outcomes relative to other periampullary malignancies, as those patients tends to manifest early due to biliary outflow obstruction, as opposed to pancreatic neoplasm that often are advanced at the time of diagnosis. Surgical resection with curative intent is the only option for long term survival. Over time, there has been much development in the treatment of patients with periampullary carcinoma. The diagnostic workup has been refined to identify potentially resectable patients at an early stage and the indication of surgery is based on computed tomography as well as magnetic resonance imaging. ${ }^{4-6}$ Surgical, endoscopic, or radiologic biliary decompression; relief of gastric outlet obstruction; and adequate pain control may improve the quality of life but do not affect overall survival rate. Most of these tumors are resectable ${ }^{2-4}$ for cure at diagnosis; the 5 year survival rate is approximately $38 \%^{5-8}$ to $67 \%$ at best ${ }^{8}$. Operative morality rates have decreased significantly over the decade because of increased surgical experience, improved anesthesia, better preoperative imaging, and better postoperative management. A good number of patients with surgical jaundice attend the surgical

1. Dr. Sarwar Ahmed Sobhan, Medical officer, Department of Surgery, Bangabandhu Sheikh Mujib Medical University (BSMMU), Dhaka.

2. Dr. Arif Salam Khan, Assistant Professor, Department of Surgery, Bangabandhu Sheikh Mujib Medical University (BSMMU), Dhaka.

3. Dr. Bidhan Chandra Das, Associate ProfessorDepartment of Surgery, Bangabandhu Sheikh Mujib Medical University (BSMMU), Dhaka.

4. Dr. Md. Mohsen Chowdhury, Professor, Department of Surgery, Bangabandhu Sheikh Mujib Medical University (BSMMU), Dhaka.

5. Dr. Md. Zulfiqur Rahman Khan, Professor and Chairman, Department of Surgery, Bangabandhu Sheikh Mujib Medical University (BSMMU), Dhaka.

6. Dr. Farzana Sharmin, Medical Officer, Department of Obstetrics \&Gynaecology, Dhaka Medical College Hospital, Dhaka.

Correspondence: Dr. Sarwar Ahmed Sobhan, Medical officer, Department of Surgery, Bangabandhu Sheikh Mujib Medical University (BSMMU), Dhaka-1000. Email:rubai.dmc59@gmail.com 
department of Bangabandhu Sheikh Mujib Medical University (BSMMU), Dhaka each year. Many of them are diagnosed later as periampullary carcinoma and receive curative or palliative surgical treatment. Most of the patients come to the unit very late stage when curative or even palliative surgery becomes almost impossible and thus, suffered from worst outcome. In this study, we tried to find the causes of delayed hospitalization of those patients and to focus the effect of this delay on the management and possible outcome.

\section{Methods}

This observational study was conducted in the Department of Surgery, Bangabandhu Sheikh Mujib Medical University (BSMMU), Dhaka, from October 2013 to March 2014. In this study, 41 patients were selected consecutively from different units especially from the hepatobiliary-pancreatic division of Surgery Department in Bangabandhu Sheikh Mujib Medical University (BSMMU), Dhaka. The patients were divided into two groups: 13 in group I (early arrival) and 28 in group II (late arrival/delayed group). Necessary data were obtained from history, physical examination, investigation reports. The patients were interviewed based on a semi-structured questionnaire.

\section{Inclusion criteria:}

1. Patients of 18 years and older (both sexes),

2. Patients with periampullarycarcinoma diagnosed pre-admission or during hospital stay.

\section{Exclusion criteria:}

1. Patients below 18 years,

2. Patients refused to give informed consent,

3. Patients with other co-morbidities,

4. Patients with other pathology that may affect the outcome.

Preoperative preparation of the jaundiced patients such as correction of anemia, maintaining adequate hydration, and improvement of nutritional status, especially by elevating the albumin level, correction of coagulopathy, control of infection (sepsis, cholangitis) is needed to achieve the anesthetic fitness and reduce postoperative mortality and morbidity. All the patients were also observed postoperatively.

\section{Results}

Table-I shows the age and sex distribution of the patients of both group I and group II. In those 41 patients, ampullary carcinoma $(65.8 \%)$ was more common than lower bile duct carcinoma (29.3\%) and duodenal carcinoma (4.9\%) among all types of periampullary carcinoma (Fig. 1).Table-II and table-III show the delay in reporting to surgical unit and causes of delay respectively. Comparison of preoperative nutritional status between group I and group II patients shows that significant loss of weight due to unusual delay in the latter. BMI was $24.32 \pm 1.32 \mathrm{~kg} / \mathrm{m}^{2}$ in group I, whereas $19.12 \pm 1.23 \mathrm{~kg} / \mathrm{m}^{2}$ in group II, hemoglobin level was $10.4 \pm 1.9 \mathrm{gm} / \mathrm{dl}$ vs $8.3 \pm 2.2 \mathrm{gm} / \mathrm{dl}$ and serum albumin level was found $3.4 \pm 0.6 \mathrm{mg} / \mathrm{dl}$ vs $2.3 \pm 0.5 \mathrm{mg} / \mathrm{dl}$ (Fig. 2). Liver function tests of the patients show worse conditions in group II in comparison to group I, as serum bilirubin and prothombin time, INR are higher than that of group I (Table-IV).In preparing the patients for surgery, need of blood transfusion, fresh frozen plasma and infusion of albumin solution were more in group II patients who delay the operative treatment, increase hospital stay and cost as well as some of them failed to get anesthetic fitness also (Table-V).Table-VIshows that all features of spread of disease like liver metastasis, ascites, lymph node involvement and seedlings are clearly evitable in group II patients indicates poor prognosis.Curative resection (Whipples procedure) is possible in $7(53.8 \%)$ cases in group I, whereas Tripple bypass is predominant in Group II which is palliative and does not changes the prognosis (Fig. 3).Table-VII shows the comparison of all the post operative complications between group I \& group II. 
Table-I

Differences of age \&sex in patients ofgroup I \& II

\begin{tabular}{lccc}
\hline Parameters & $\begin{array}{c}\text { Group I } \\
(\mathrm{n}=13)\end{array}$ & $\begin{array}{c}\text { Group II } \\
(\mathrm{n}=28)\end{array}$ & $\begin{array}{c}\mathrm{P} \\
\text { value }\end{array}$ \\
\hline Age (years) & $52.4 \pm 13.3$ & $51.8 \pm 15.7$ & $\mathrm{~ns}$ \\
Sex (M:F) & $8: 5$ & $15: 13$ & $\mathrm{~ns}$ \\
\hline
\end{tabular}

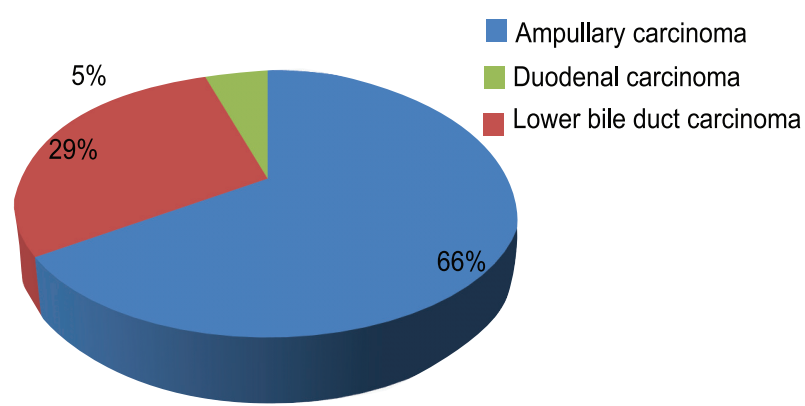

Fig. 1: Distribution of different type of periampullary carcinoma

Table-II

Received treatment before coming to surgical unit

Types of treatment Duration (in days) Treatment received

(Number of patients)

\begin{tabular}{lcl}
\hline Traditional treatment $(\mathrm{n}=21)$ & $17.5 \pm 8.2$ & Hand washing, herbal medication \\
General physician $(\mathrm{n}=41)$ & $21.8 \pm 9.2$ & $\begin{array}{l}\text { Rest, IV glucose saline, laxative, vitamins, } \\
\text { ursodcoxycolioc acid, antiemetic etc. }\end{array}$ \\
Specialist physician $(\mathrm{n}=14)$ & $120.6 \pm 148.8$ & ERCP + steting ERCP + papillotomy Failed ERCP \\
\hline
\end{tabular}

Table-III

Causes of delay to report a surgeon (answer noted from patients and/ relativesin interview)

1. Ignorance, superstition and fear of operative treatment for jaundice by the patient himself/ herself.

2. Delay in diagnosis periampullary carcinoma as cause of jaundice and treated as medical jaundice for a period of time.

3. Immediate relief of jaundice by ERCP and stenting procedure by specialist physician and patient not consulting surgeon in time even after counseling by specialist physician to attend a surgeon for further treatment.

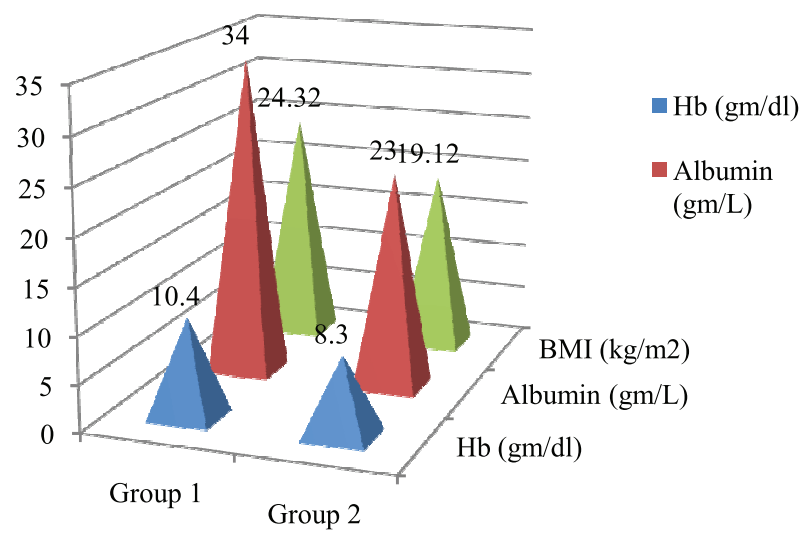

Fig.-2: Differences in preoperative nutritional assessment in patients of group I \& II
Table-IV

Differences in preoperative laboratory findings in patients of group I \& II

\begin{tabular}{lccc}
\hline $\begin{array}{l}\text { Liver function } \\
\text { tests }\end{array}$ & Group I & Group II & $\begin{array}{c}\text { P } \\
\text { value }\end{array}$ \\
\hline $\begin{array}{l}\text { Total Bilirubin } \\
\text { (mg/dl) }\end{array}$ & $11.2 \pm 4.0$ & $23.6 \pm 8.3$ & $<0.01$ \\
$\begin{array}{l}\text { Alkaline Phos- } \\
\text { phatase (U/L) }\end{array}$ & $565.0 \pm 230.3$ & $533.1 \pm 353.2$ & $\mathrm{~ns}$ \\
$\begin{array}{l}\text { Prothombin Time } \\
\text { (Sec) }\end{array}$ & $17.5 \pm 2.3$ & $27.8 \pm 7.7$ & $<0.01$ \\
INR & $1.52 \pm 0.21$ & $2.7 \pm 1.0$ & $<0.01$ \\
$\begin{array}{l}\text { Tumor marker } \\
\text { CA 19-9 (U/L) }\end{array}$ & $546.5 \pm 794.4$ & $658.1 \pm 1356.1$ & $\mathrm{~ns}$ \\
\hline
\end{tabular}


Table-V

Differences of required materials for preparing a patient for surgery between group I \& II

\begin{tabular}{lccc}
\hline Parameters & Group I $(\mathrm{n}=13)$ & Group II $(\mathrm{n}=28)$ & P value \\
\hline Blood requirement (Unit) & $1.3 \pm 0.9$ & $2.6 \pm 1.3$ & $<0.05$ \\
Albumin requirement (25\% albumin of $100 \mathrm{ml})$ & $2.0 \pm 1.5$ & $3.7 \pm 1.4$ & $<0.05$ \\
FFP requirement (Unit) & $1.8 \pm 01.9$ & $5.4 \pm 1.7$ & $<0.001$ \\
Fail to achieve anesthetic fitness for surgery & $0(0 \%)$ & $05(17 \%)$ & $<0.05$ \\
\hline
\end{tabular}

Table-VI

Differences of par operative findings between Group I \& II

\begin{tabular}{lccc}
\hline Parameters & Group I $(\mathrm{n}=13)$ & Group II $(\mathrm{n}=28)$ & P value \\
\hline Ascites & $2(15.0 \%)$ & $11(47.8 \%)$ & $<0.001$ \\
Liver metastases & $1(7.5 \%)$ & $7(30.4 \%)$ & $<0.01$ \\
Peritoneal seedling & - & $3(13.0 \%)$ & $\mathrm{ns}$ \\
Lymph node enlargement & $3(23.0 \%)$ & $9(39.1 \%)$ & $\mathrm{ns}$ \\
\hline
\end{tabular}

Table-VII

Post operative complications between group I \& group II

\begin{tabular}{lccc}
\hline Parameters & Group I $(\mathrm{n}=13)$ & Group II $(\mathrm{n}=28)$ & P Value \\
\hline Perioperative mortality (within hospital stay) & - & 03 & $<0.001$ \\
Peri operative morbidity & 03 & 16 & $<0.01$ \\
Wound infection & 01 & 11 & $<0.01$ \\
Pancreatic fistula & - & 04 & $<0.01$ \\
Hepatic dysfunction & - & 09 & $<0.01$ \\
Pneumonia & 01 & 04 & $<0.01$ \\
Delayed gastric emptying & 01 & 02 & $\mathrm{~ns}$ \\
Overall hospital stay (average) & 2 weeks & $3-4$ weeks & $<0.01$ \\
\hline
\end{tabular}

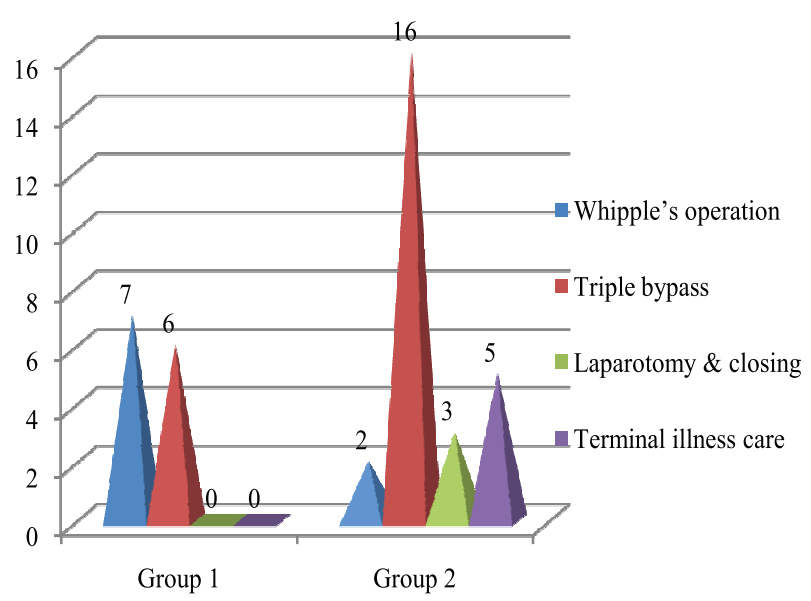

Fig. 3: Differences of operative procedure done between Group I \& II

\section{Discussion}

Prognosis of periampullary carcinoma is better than carcinoma head of the pancreas ${ }^{1}$. The $5-$ year survival rate of periampullary carcinoma varies from 38 to $67 \%^{5-8}$, whereas the 5 - year survival rate of pancreas head carcinoma varies from 9 to $17 \%{ }^{9,10}$. The reason of long term survival of periampullary carcinoma are:i)these patients develop jaundice at the earlier part of the disease.Because of early appearance of jaundice patient seek medical attention earlier, ii) curative resection is possible in most of the time as they seek surgical attention earlier. Incidence of periampullary carcinoma in our study was 41 patients $(n=41)$, as ampullary cancer $27(65.8 \%)$, 
lower bile duct cancer 12 (29.3\%), and duodenal cancer were $2(4.9 \%)$; i.e. ampullary carcinoma are more common than the other two. However, there was no significant difference in age and sex distribution of patients between two groups. It was found that mostly periampullary carcinoma occurs at $5^{\text {th }}$ and $6^{\text {th }}$ decades of life and male $\&$ female predominance was equal. Unfortunately these patients come to surgical unite very lately for surgical management in our country. Because of ignorance and superstition most patients seek herbal treatment at the earlier part of their illness. Although medical jaundice mostly cured gradually because of natural course of the disease, surgical jaundice is worsen gradually if intervention is not taken in time. Thus patient who is suffering from surgical jaundice spent on an average of 2 week time for traditional treatment as seen in our study. When herbal treatments completed without any improvement, the general physician's role is crucial in managing jaundiced patient as they are the first contact point for proper identification, appropriate treatment and proper referral. Patient should be investigated carefully to indentify medical or surgical jaundice correctly. Thus a general physician can treat these patients correctly or can refer the patient to a proper place. The result of interviewing patients and relatives for finding out the cause of delay referral are: i) patients believe that the jaundice is often cured by taking traditional medicine; therefore they spend 2-3 week time for traditional treatment shown in the initial part of their illness, ii) patients attend registered physician when jaundice is not improved by traditional treatment. Physician starts treatment conservatively and evaluates jaundice through investigations. When physician understand that they are suffering from obstructive jaundice, they refers them to specialist physician and thus patients spend another 23 weeks or more time with general physician, iii) Specialist physician like the gastroenterologist often treated those patients by ERCP and stenting or papillotomy or whatever is possible with a view to relief the jaundice on temporary basis and improve the liver function. Patients also choose nonsurgical but invasive procedure comfortably. They ask the patients to consult with surgeon for possible surgical treatment after stenting. But most of the time patient do not consult surgeon in time for two reasons, a) jaundice decrease after the procedure and they feel better than earlier time, b) they are afraid of taking operative treatment for jaundice. Finally they come to surgeon when jaundice reappears due to cholangitis, blockage of stent, or spread of malignancy. Obstructive Jaundice patients should be evaluated for surgery before doing any internal biliary drainage procedure. Several prospective randomized controlled clinical trials ${ }^{11-13}$ in Western countries have concluded that preoperative biliary decompression is unnecessary. It has been reported to increase the incidence of complications following surgery and to worsen the outcome of jaundice patients. Pitt et al. ${ }^{14}$ reported that there were no differences between the postoperative morbidity and mortality rates of the obstructive jaundice patient who either underwent prior biliary decompression or did not undergo decompression. Moreover, performing decompression significantly increase hospital costs. A review of preoperative external drainage from 1974 to 1984 by Gouma\& Moody ${ }^{15}$ concluded that the hazards of the technique outweighed any possible advantages, and most surgeons subsequently abandoned this procedure. However there are few Japanese reports ${ }^{16-18}$ those were in favor of biliary decompression. Some Japanese believes prior biliary decompression is required only when hepatectomy or hepato-pancreatodeoenectomy is planned for managing surgical jaundice patient ${ }^{19}$.

Medical specialist routinely performs ERCP and /or place a sent in common bile duct whenever possible for reduction of jaundice without taking any prior surgical opinion in our country. Disadvantages of routine ERCP and CBD stenting procedure are; most patients don't come to surgeon for surgical treatment in time although specialist physician ask patient to visit surgeon. Patients are reluctant to receive surgical treatment as jaundice decrease after 
the procedure and they feel better than before. Many of patients are also expressed that they did not visit surgeon as they are afraid of surgery. Thus, most of the patient moves through this chain and makes a delay of receiving surgical treatment.

In the present study, there was no significant difference in respect to age and sex of patients between two groups. However, mostly periampullary carcinoma occurs at 5 th and 6 th decades and male $\&$ female predominance were equal. From the above study, it is clear that the patients who came earlier to surgical unit had a significantly good nutrition status (hemoglobin, serum albumin level and BMI) and liver function than who came late. As hemoglobin is the most important factor for tissue perfusion and anemia can delay the wound healing and tissue, ischemia can affect the major surgery seriously. Albumin indicates the synthetic function of liver. Poor albumin level indirectly proves the altered hepatic status of those patients. Ultimately, the unusual delay in hospitalization affects the overall outcome and increases the perioperative mortality and morbidity.

Very high level of bilirubin has detrimental effect on cancer patients. Direct bilirubin may precipitate on Bowman's capsule and can cause decrease GFR which leads to hepato-renal syndrome. Poor liver function also contributes to at risk recovery after prolonged surgery like Whipples procedure. On the other hand, altered coagulation profile indicates chance of bleeding from various sites. So, these patients may bleed during surgery and subsequently developed shock within short duration.

Disease spread was more common in late group than early arrival group. As we found preoperatively, ascites, liver metastasis, positive lymph node and peritoneal seeding all the features of metastasis were more common in delayed hospitalized patients. Hence, curative surgery was abandoned and only possible palliations were done. On the other hand, appropriate treatment like Whipple's procedure as curative resection was possible more frequently in earlier group than late one. Whereas most of the patients of group II had experience palliative biliary and gastric bypass or only Laparotomy due to metastasis or poor prognosis. Patients who were not even fit for any sort of surgical treatment due to very poor liver function and nutritional status were referred to palliative care unit for terminal care treatment. Both postoperative mortality and morbidity were frequently occurred in delayed hospitalized patients and they stayed in the hospital longer than expected, which increased the hospital cost.

Limitations: Small sample size with narrow study period cannot successfully throw light on the focus of the study. To find out the actual causes of delayed hospitalization, it needs a larger sample size with long time study so that patients from different economic status and educational background can be judged with the parameters. Since the patients were selected just before their surgical interventions, survey of etiological aspect and past treatment history could not be done properly. Delayed complications and long term outcome of surgery could not be ascertained in the study in terms of recurrence and redo-surgery. This study lacks enough demographic, clinical and biochemical data also. In our socio-economic background most of the patients are poor and illiterate, so their awareness and ability to achieve surgical treatment of obstructive jaundice is less than other countries which is really difficult to explain in this limited boundary of study.

Recommendations: On the basis of our result, we would like to recommend that proper treatment can be given to patients with periampullary carcinoma if they come to surgical unit at the earlier part of noticing jaundice.Awareness of people as well as general physicians who are dealing with jaundiced patients is required for early diagnosis and referral of patients with periampullary carcinoma to surgery. Joint assessment of these patients by Gastroenterologist and Hepatobiliary surgeons before internal biliary drainage will improve prognosis.

\section{Conclusion}

From our study, we could realize that patients with periampullary carcinoma presented with 
features of obstructive jaundice hospitalized long after appearing symptoms. They spent much time on delayed diagnosis, maltreatment and overall delayed or inappropriate referral. Patient's awareness and economical affordability are crucial factor in choosing the correct surgical treatment of obstructive jaundice. Hence, our concernsare to improve the early diagnosis as periampullary cancer presented early than others, to refer them to such a place where possible surgical curative treatment can be performed at an earliest date and to get the best perioperative outcome.

\section{References}

1. Beger HG, Poach B, Rau BM. Surgical treatment of periampullary cancer: early and late results after resection. In: The pancreas: an integrated text book of basic science, medicine and surgery.2nd ed. New York: BlackWe11; 2008: p.885-9.

2. Beger HG, Thorab FC, Liu $Z$, et al.Pathogeenesis and treatment of neoplastic disease of the paplilla of Vater: Kausach-Whipple procedure with lymp node dissection in cancer of papilla of Vater. $J$ Hepatobiliary PancreatSurg2004;11:232-8.

3. Waren KW, Choe DS, Plaza J, RelihanM. Result of radical resection ofPeriampullary cancer. Ann Surg 1975; 181:534-40.

4. Yamaguchi K, Enjoji M. Carcinoma of the ampulla of the Vater: a clinicopathologicalstudy and pathologic staging of 109 case of carcinoma of 5 case of adenoma. Cancer 1987;59:506-15.

5. Talamini MA, Moesinger RC, Pitt HA, et al. Adenocarcinoma of the ampulla Vater: a 28- year experience. Ann Surg.1997;225:590-600.

6. Nakagawa T, Kayahara M, Ikeda S et al. Biliary tract cancer treatment: result from the biliary tract cancer statistics registry in Japan. J Hepatobiliary PancreatSurg 2002;9:569-75.

7. Di Giorgio A, Alfieri S, Rotondi F, et al. Pancreatoduodenectomy for tumors of Vater's ampulla: report on 94 consecutive patients. World Surg2005;29:513-8.
8. Duffy JP, Hines OJ, Liu JH, et al. Improved survival for adenocarcinoma of the ampulla of Vater: Fifty-five consecutive resections. Arch Surg2003;138:941-50.

9. Ishikawa O. Ohigashi H, Sasaki Y et al. Practical usefulness of lymphatic and connective tissue clearance for the carcinoma of the pancrease head. Ann Surg 1988; 208: 215-20.

10. Mu DQ, Peng SY, Wang GF. Extended radical operation of pancreatic head cancer: appraisal of its clinical significance. World J Gastroentrol 2005;11:2467-71.

11. Hatfield AR, Terblanche J, Fattar S, et al. Preoperative external biliary drainage in obstructive jaundice. Lanect 1982;11:896-9.

12. McPersonGAD, Benjamin IS, Hodgson HJF, et al. preoperative precutaneoustranshepatic biliary drainage; result of a controlled trial. $\mathrm{Br} \mathrm{J}$ Surg 1984;71:371-5.

13. Sirenek KR, Levine BA. Percutaneous transhepatic cholangiography and biliary decompression. Arch Surg1989; 124:885-8.

14. Pitt HA, Gomes AS, Lois JF, et al. Does preoperative percutaneous transhepatic biliary drainage reduce operative risk or increase hospital cost? Ann Surg1984;201:545-53.

15. Goumma DJ, Moody FG. Preoperative percutaneous transhepatic biliary drainage; use or abuse. SurgGastroenterol 1984;3:74-80.

16. Nakayama T, Ikeda A, Okuda K . Percutaneous transhepatic drainage of the biliary tract. Technique and results of 104 cases. Gastroenterology. 1978;74:554-9.

17. Takada T, Hanyu F, Kobayashi S, et al. Percutaneous transhepaticcholangio drainage: direct approach under fluoroscopic control. J SurgOncol 1987;8:83-97.

18. Kawarada Y, Higsahiguci T, Yokoi H, et al. Preoperative biliary drainage in obstructive jaundice. Hepatogastroenterology 1995;42: 300-7.

19. Kawarada Y, Das BC. Should biliary decompression be performed prior to major hepatectomy for malignant biliary obstruction? Ann CollSurg HK 1998; 2: 1. 